\title{
Mapping daily evapotranspiration over a Mediterranean vineyard watershed
}

\author{
Mauricio Galleguillos, Frédéric Jacob, Laurent Prévot, Philippe Lagacherie, Shunlin Liang
}

\begin{abstract}
Daily Evapo-Transpiration (ET) was mapped and validated at the regional extent over a vineyard landscape. The mapping was performed using the S-SEBI model along with ASTER imagery over two growth cycles. The validation exercise was conducted within a Mediterranean vineyard watershed, over seven sites that differed in canopy, soil and water conditions. Despite the use of a very simple model over a complex row structured landscape, the obtained accuracy $\left(0.8 \mathrm{~mm} . \mathrm{d}^{-1}\right)$ was similar to those reported over simpler canopies with full covers, and corresponded to requirements for further applications in agronomy and hydrology, where daily ET can be assimilated into land surface models for calibration and control purposes. An analysis of the validation results suggested that, amongst the possible factors that could affect S-SEBI performances (spatial variability, vine water status, soil type and color, row orientation), the first order influence was row orientation.
\end{abstract}

Index Terms-Vineyard watershed, daily evapotranspiration, ASTER, HYDRUS-1D, S-SEBI.

\section{INTRODUCTION}

Land surface evapotranspiration (ET) is a key variable in hydrology and agronomy, where the involved processes are driven by micrometeorology and soil moisture, amongst others. Knowledge of daily ET is paramount for determining crop water use which represents up to $70 \%$ of the yearly water balance within semiarid watersheds [1]. Since they are mostly rainfed, Mediterranean vineyards experience severe water stress, especially in summer when evaporative demand is maximal and rainfalls are negligible. Water stress is needed to regulate vine metabolism, but excessive stress can cause severe damage to production. Vineyard daily ET and vine water status should therefore be diagnosed at appropriate growth stages and forecasted under expected climate changes.

Most attempts to estimate vineyard daily ET addressed the field scale [2], whereas the consideration of larger scales from remote sensing focused on vine physiological conditions only [3]. On the other hand, the numerous models that have been developed to map daily ET from optical remote sensing have been mostly used over full cover homogeneous canopies [4], with a desired accuracy of $0.8 \mathrm{~mm} . \mathrm{d}^{-1}$ [5].

Row structured vineyards present specific problems for estimating ET, such as the impact of turbulence within canopy and inter-row on convective fluxes, or the influence of shade

Manuscript received Month, Day, Year; revised Month Day, Year.

M. Galleguillos, L. Prévot and P. Lagacherie are with INRA / UMR LISAH, 34060 - Montpellier, France (email: gallegui@supagro.inra.fr; laurent.prevot@supagro.inra.fr; philippe.lagacherie@supagro.inra.fr).

F. Jacob is with IRD / UMR LISAH, 34060 - Montpellier, France (email: frederic.jacob@supagro.inra.fr).

S. Liang is with Department of Geography, University of Maryland, College Park, MD, USA (email: sliang@umd.edu). effects on remote sensing data. It seems relevant to use a two source model that splits soil and vegetation, with additional differentiating between sunlit and shaded parts [6], but parameterization complexities can induce large errors. An alternative is to derive ET from surface temperature differences rather than from absolute values, thus minimizing data and parameterization errors. Based on spatial contrasts, such differencing methods benefit from variations captured with high spatial resolution sensors [7], where Advanced Spaceborne Thermal Emission and Reflection Radiometer (ASTER) uniquely offers high quality spaceborne data of surface temperature [8].

Amongst differencing methods, such as the Surface Energy Balance Index (SEBI) [9] or the Water Deficit Index (WDI) [10], the Simplified-SEBI (S-SEBI) [11] is characterized by its simplicity and feasibility, and is therefore a good candidate for operational purposes. It has been applied over various agrosystems [12], [13] and at different spatial resolutions [14], [15]. Its assessment over vineyards is of interest since the model relies on temperature differences and albedo only, thus avoiding delicate computations of biophysical variables.

This paper reports the first results obtained when mapping daily ET over vineyards by using S-SEBI along with ASTER optical imagery over two growth cycles. Validation relies on ground based estimates at sites that differ in canopy structure, soil properties and watertable level. We first present the study site ( $\S$ II-A), methodology for both the ground based and the remotely sensed estimations ( $\S$ II-B \& II-C) and the validation strategy $(\S \mathrm{III})$. We next report results from the ground based $(\S \mathrm{IV}-\mathrm{A})$ and the remotely sensed ( $\S$ IV-B) estimations.

\section{MATERIALS AND METHODS}

\section{A. Study site}

The Peyne watershed $\left(43.49^{\circ} \mathrm{N}, 3.37^{\circ} \mathrm{E}, 80 \mathrm{~m}\right.$ asl) is located in the Languedoc - Roussillon region of southern France. This $65 \mathrm{~km}^{2}$ size watershed contains vine mono-cultures $(70 \%)$ over flat terrains, mostly rainfed $(>95 \%)$, while the remaining $30 \%$ includes olive and wheat crops, forests, native scrubland and urban zones. Yearly Penman ET is close to $1100 \mathrm{~mm}$, and annual rainfalls range between 400 and $1300 \mathrm{~mm}$ [16].

The area is heterogeneous in soil type (with various parent materials) and watertable level. To capture this variability for validation purposes, seven sites were selected, corresponding to rainfed vineyards with similar trellis structures apart from row orientation (Tab. I). Each of Site 1 to 5 and 7 spread over one field, with size ranging from 0.03 to $0.09 \mathrm{~km}^{2}$. Site 6 had a $0.15 \mathrm{~km}^{2}$ size and spread over nine fields that included vineyards by $90 \%$ in surface area. It was split into a north $(6 \mathrm{~N})$ and a south $(6 \mathrm{~S})$ sub-site for validation purposes. 
TABLE I

VALIDATION SITE FEATURES WITH PREDOMINANT SOIL TEXTURE, WATERTABLE CONDITIONS, AND ROW ANGLE (NORTH AS ORIGIN).

\begin{tabular}{lllll}
\hline Site & $\begin{array}{l}\text { Soil } \\
\text { texture }\end{array}$ & $\begin{array}{l}\text { Watertable } \\
\text { conditions }\end{array}$ & $\begin{array}{l}\text { Row } \\
\text { angle }\left(^{\circ}\right)\end{array}$ & $\begin{array}{l}\text { Canopy } \\
\text { structure }\end{array}$ \\
\hline 1 & Sandy, Silty & Absent & -17 West & Row spacing: \\
2 & Clay, Gravels & Intermittent & +42 East & $2.5 \mathrm{~m}$ \\
3 & Silty, Sandy & Absent & -34 West & \\
4 & Clay Loam & Permanent & +24 East & Row width \\
5 & Clay & Intermittent & +35 East & (max): $1 \mathrm{~m}$ \\
$6 \mathrm{~N}$ & Clay loam & Intermittent & +85 East & \\
$6 \mathrm{~S}$ & Silty & Absent & -01 West & Row height \\
7 & Clay & Absent & -42 West & $1.22-1.75 \mathrm{~m}$ \\
\hline
\end{tabular}

\section{B. Ground based estimates of daily ET}

Amongst the possibilities for in-situ estimation of daily ET, we chose an alternative that minimized experimental efforts. It made use of the HYDRUS-1D model that simulates water transfers in the vadose zone after calibration against soil moisture profiles, provided meteorological forcing is known.

1) Field data:

Hourly values of air temperature, wind speed, relative humidity, solar irradiance and rainfall were collected at Site 6 with a CIMEL ENERCO 400 station, following meteorological standards apart from wind speed (measured at $2 \mathrm{~m}$ height rather than $10 \mathrm{~m}$ ). Hourly net radiation was measured over a representative vineyard within Site 6 using a Campbell NRlite device whose footprint was up to $66 \%$ vine canopy.

Each site was monitored for vegetation, watertable and soil moisture, biweekly and after rainfalls. Vegetation was monitored for canopy height and width. Watertable level was monitored down to $2.5 \mathrm{~m}$ with manual piezometric devices. The number of locations for collecting soil moisture profiles varied according to soil heterogeneity from a pedological map and to site size: one location for Site 1, 2, 4, 7; two locations for Site 3 and 5; and nine locations for Site 6. Profiles were sampled every $0.2 \mathrm{~m}$ down to $2.5 \mathrm{~m}$ with a Vectra 503-DR CPN Neutron Probe (NP) device, and completed for the top $0.15 \mathrm{~m}$ using a Soil Moisture Equipment TRASE 6050 TDR.

Eddy Covariance (EC) devices were setup within two sites that differed in soil properties and watertable level: a permanent flux tower (Site 6) and a temporary flux tower for three day windows around ASTER overpasses (Site 7). Each tower included a R.M. Young 81000 3D sonic anemometer and a fast hygrometer (Licor LI7500 for Site 6 and Campbell KH2O for Site 7). For Site 6 (resp. Site 7), that spread over nine (resp. one) fields, the sensors were setup $5.7 \mathrm{~m}$ (resp. $1.5 \mathrm{~m}$ ) above canopy and acquisition frequency was $10 \mathrm{~Hz}$ (resp. $20 \mathrm{~Hz}$ ). Sensible and latent heat fluxes were calculated over hourly intervals by applying double rotation and instrumental corrections from the ECPACK 2.5.20 library [17]. Fluxes were calculated with tolerance intervals, about $20 \%$ and $12 \%$ for Sites 6 and 7. For energy balance closure, convective fluxes and available energy agreed within $80 \%$ in relative. Daily ET was finally calculated as the sum of hourly ET.

Ground based data were collected from August 2007 to October 2008. Each instrument was manufacturer calibrated. The NP device was calibrated by accounting for soil type and moisture. Calibration was performed against gravimetric soil moisture data at each measurement depth (soil density was estimated using a Campbell DR 501 gamma probe), with a residual error of $0.04 \mathrm{~m}^{3} \cdot \mathrm{m}^{-3}$ (15\% relative error).

2) The HYDRUS-1D model:

HYDRUS-1D is a deterministic model that simulates water transfers in the vadose zone from Richards equation [18]. Actual plant transpiration is estimated as the sum, over soil layers, of water uptake by roots, where the latter is derived from maximum transpiration through a reduction coefficient that depends on moisture. Actual soil evaporation is derived from potential evaporation according to surface pressure head.

Rainfalls were measured at the meteorological station ( II-B1). Maximum transpiration and potential evaporation were derived from reference ET using Riou's model designed for vineyards [19], [16], [20]. Following [19], reference ET was derived from meteorological data by using the Penman formulation under standard conditions. Then Riou's model inferred potential transpiration as a fraction of reference ET (potential evaporation was the residual), by assuming this fraction almost equals the ratio of solar radiation absorbed by vine leaves to that absorbed by the whole vineyard. For this, solar irradiance absorbed by leaves was geometrically derived from solar position and canopy structure (see Tab. I), and vegetation albedo was set to 0.2. Maximum transpiration was set to potential transpiration, which was within the confidence interval reported by [16] who suggested a $10 \%$ larger value.

The soil was split into $N$ horizons including topsoil ( $N \in$ [2-4] following in-situ observations and expert knowledge), and discretized into 251 layers between 0 and $2.5 \mathrm{~m}$ depth. Root density was distributed according to in-situ observations and previous studies [16], [20]. The resulting averaged profile considered $75 \%$ of roots between 25 and $125 \mathrm{~cm}$, with a $2.2 \mathrm{~m}$ maximum depth. The reduction coefficient for transpiration was parameterized using the Feddes functions [21], along with threshold pressures of -0.1 and -1.5 mbar for potential root water uptake [16]. Lower boundary conditions were set to free outflow when piezometric data indicated watertable absence, and to the fixed pressure head at the watertable level otherwise.

For each soil horizon, unsaturated hydraulic conductivity and retention curves were characterized using van Genuchten functions that depend on residual $\theta_{r}$ and saturated $\theta_{s}$ soil moisture, on saturated hydraulic conductivity $K_{s}$, on bubbling pressure $\alpha$ and on the pore-size distribution index $n$ [22]. $\theta_{r}$ and $\theta_{s}$ were set to maximal and minimal moisture values observed from NP data. Topsoil $\alpha, K_{s}$ and $n$ were estimated following former studies over the Peyne watershed [16], [20]. For deeper horizons, they were estimated using the HYDRUS1D calibration mode that minimized the differences between measured and simulated soil moisture profiles over the simulation period. Initial guesses were derived from literature values proposed for similar soils when possible [16], [20], and from the HYDRUS-1D ROSETTA module otherwise.

For each location of NP measurements ( $\$$ II-B1), HYDRUS1D was calibrated against the NP data collected between August 2007 and October 2008. Hourly simulations accounted for changes in illumination, and the resulting ET was totaled at the daily scale. Calibration relied on noon values, since NP data acquisition periods were centered on noon. 


\section{Remote sensing estimates of daily ET}

1) ASTER estimates of land surface radiative variables: We used ASTER official products for surface reflectance, waveband emissivity and radiometric temperature, whose accuracies were 5\%, 0.01 and $1.5 \mathrm{~K}$ respectively [23], [24]. These products resulted from 11 cloud-free sets of images sunsynchronously collected around nadir viewing at 11:00 UTC in 2007 (DOY 226, 258, 306) and 2008 (DOY 174, 190, 197, 206, 213, 245, 270, 277). Reflectances at $15 \mathrm{~m}$ (visible and near infrared) or $30 \mathrm{~m}$ (shortwave infrared) were averaged at the $90 \mathrm{~m}$ resolution of emissivity and radiometric temperature. Images were carefully geolocated against aerial orthophotos.

ASTER albedo was computed as a linear combination of reflectances. Due to deficient shortwave infrared channels in 2008, the generic two channel formulation from [25] was linearly corrected against the ASTER seven channel formulation from [26]. The correction was calibrated over the 2007 dataset (relative residual error of 6\%). ASTER broadband emissivity was computed as a linear combination of channel emissivities following [27]. Finally, ASTER net radiation was classically computed following [7]. In addition to albedo, broadband emissivity and radiometric temperature, this required meteorological data about solar irradiance, and about air temperature and humidity for deriving atmospheric irradiance [20].

2) The S-SEBI model:

Below is a model overview, see [11], [12], [14], [15] for detailed descriptions. Deriving daily ET $E T_{d}$ from S-SEBI along with optical imagery, where the latter captures contrasts driven by evaporation processes, is twofold. Evaporative fraction $\Lambda$, the ratio of latent heat flux to available energy, is computed from the differences between pixel temperature $T_{S}$ and maximum $\left(T_{\max }\right)$ and minimum $\left(T_{\min }\right)$ temperatures within the corresponding albedo class. Next, assuming the instantaneous $\Lambda$ at satellite overpass is equal to the daily $\Lambda$, and neglecting daily soil heat flux, $E T_{d}$ is derived by extrapolating, at the daily scale, instantaneous net radiation at satellite overpass $R_{n i}$, through the ratio $C d_{i}=R_{n d} / R_{n i}$ where $R_{n d}$ is daily net radiation ( $L$ is latent heat of vaporization):

$$
E T_{d}=\Lambda \frac{R_{n d}}{L}=\frac{T_{\max }-T_{S}}{T_{\max }-T_{\min }} \frac{C d_{i} R_{n i}}{L}
$$

To implement S-SEBI with the ASTER data, the temperature - albedo space was characterized by calculating, for each $10^{-3}$ width albedo class, albedo mean value and extreme temperatures. Next, $T_{\max }$ upper (resp. $T_{\min }$ lower) limit was determined from the linear regression between albedo class mean value and maximum (resp. minimum) temperature. As originally proposed by [11], $T_{\max }$ upper limit was computed by excluding albedoes below the threshold value corresponding to the maximum temperature of the concave temperature albedo relationship [28]. To reduce noise influence, $T_{m i n}$ lower limit was computed by including all albedoes [15]. To include all (temperature, albedo) pairs within the outer limits, an offset was added to $T_{\max }$ (resp. subtracted to $T_{\min }$ ) regression line, where the offset corresponded to the variability of maximum (resp. minimum) temperature over albedo classes.

Following [12], coefficient $C d_{i}$ was calibrated on a daily basis from in-situ measurements of net radiation within Site 6

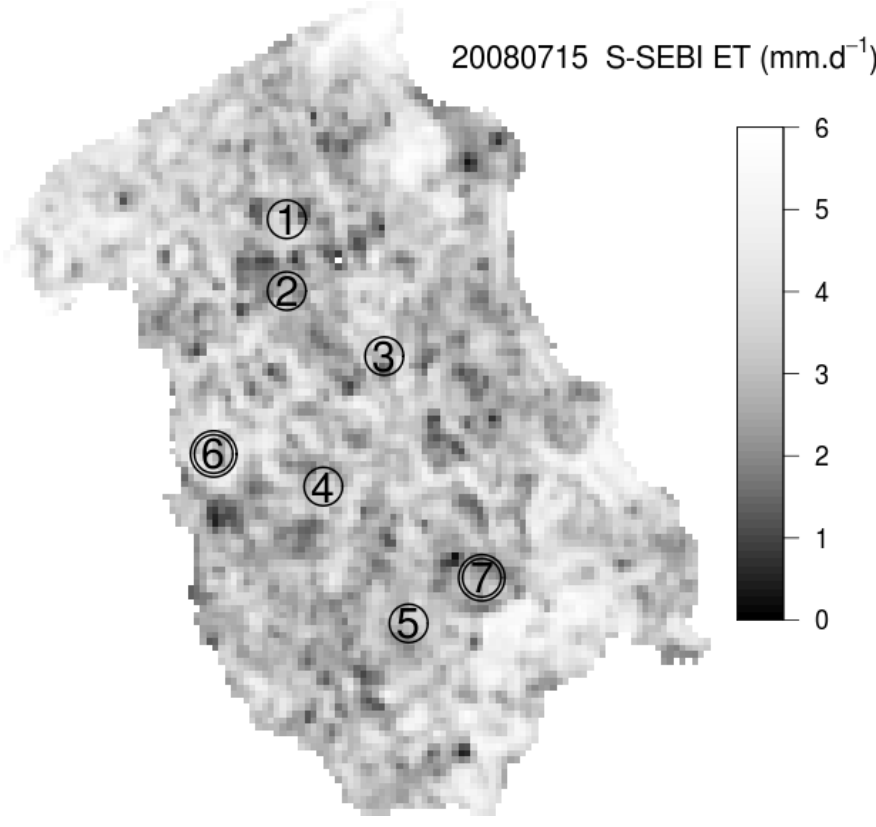

Fig. 1. Daily ET map over the Peyne watershed on July, 15, 2008. Validation sites are numbered 1 to 7 , and those with EC devices are double circled.

(§ II-B1). Calibrated $C d_{i}$ depended on satellite overpass time, and was assumed to be uniform within the Peyne watershed.

Capturing spatial contrasts within the watershed was consistent with the presence of bare soils, forests, rivers and water bodies. Thus, deriving evaporative fraction from temperature differencing assumed similar micrometeorological and aerodynamic conditions for all surfaces, in spite of differences in roughness length, wind speed and air temperature. The resulting errors were expected to be low, according to previous works on heterogeneous patchworks [12], [15], [13].

\section{ASSESSMENT AND VALIDATION STRATEGY}

Fig. 1 displays an example of the daily ET maps we obtained. A large range of ET values (1 to $7 \mathrm{~mm} . \mathrm{d}^{-1}$ ) was observed in time and space for validation sites, which confirmed the latter were appropriate for capturing variations (§ II-A). First, we inspected HYDRUS-1D simulations, by $1 /$ quantifying residual error on model calibration, and 2/ comparing simulations against EC measurements. For comparison over Site 6, we averaged the nine HYDRUS-1D simulations that corresponded to the locations of NP measurements within the footprint of EC measurements. Second, we compared the ASTER / S-SEBI estimates against the HYDRUS-1D simulations, by differentiating years and sites. For comparison over sites with two locations of NP measurements, we averaged the HYDRUS-1D simulations. For comparison over Site 6, HYDRUS-1D simulations were averaged for each sub-site $6 \mathrm{~N}$ and 6S (§ II-A). From an ASTER viewpoint, we extracted each pixel matching to a site or a sub-site.

\section{RESUlTS AND DISCUSSION}

\section{A. Assessing quality of ET ground based estimates}

When averaged over all dates and locations of NP measurements, the profile of Root Mean Square Error (RMSE) 
between measured and simulated soil water content showed a decrease with depth from 0.06 to $0.03 \mathrm{~m}^{3} \cdot \mathrm{m}^{-3}$ (30 and $10 \%$ in relative), which was ascribed to temporal stability of deep soil moisture. Largest values around $1 \mathrm{~m}$ depth were imputed to moisture variations in relation to root water uptake. When averaged over each profile, RMSE between measured and simulated soil water content varied between 0 and $0.15 \mathrm{~m}^{3} \cdot \mathrm{m}^{-3}(0 \%$ and $60 \%$ in relative) from one date and one location to another. For a given location, RMSE diminished with simulation time, which may result from errors in HYDRUS-1D initialization. Lowest (resp. largest) RMSE was observed within Site 4 (resp. Site 1), but no link was found with watertable conditions or soil types (Tab. I). When focusing on temporal changes in soil water storage (i.e. integrated soil moisture profile) at noon, relative RMSE between measurements and simulations was lower than $10 \%$ regardless of date and location. This was acceptable, given i) the large suite of conditions in soil and watertable, and ii) the errors on NP data, about $15 \%$ in relative ( $\S$ II-B1).

For Site 7 , characterized by a strong water constraint related to a clay soil with no watertable (Tab. I), RMSE between HYDRUS-1D estimates and EC measurements of daily ET was $0.4 \mathrm{~mm} . \mathrm{d}^{-1}$ (18\% in relative). For Site 6 with a moderate water constraint, RMSE was 0.57 mm.d ${ }^{-1}$ (33\% in relative). The larger RMSE observed for Site 6 was ascribed to a larger amount of data (nine locations of NP measurements). Over both sites, HYDRUS-1D simulations overestimated EC estimates for large ET values after lengthy and large rainfalls, whereas absolute RMSE was quite stable over the simulations. Overall, these results were acceptable, since the two estimates were independent, based either on near surface turbulent fluxes or on vadose-zone water transfers.

From i) calibration results that involved various hydrodynamic conditions, and ii) comparison against independent EC data, we underlined the consistency of HYDRUS-1D simulated daily ET. This made it possible to use the latter as ground based reference for validating remotely sensed estimates.

\section{B. Validating ASTER / S-SEBI estimates of daily ET}

The first step focused on net radiation which is a key variable in S-SEBI calculation (§ II-C2). Validation of ASTER estimates against in-situ data collected within Site 6 (§ II-B1) provided a RMSE of $45 \mathrm{~W} . \mathrm{m}^{-2}$, which may be explained by differences between soil and vegetation portions within the NR-lite footprint and ASTER pixels (66\% versus 40\%). The second step aimed to quantify the standard deviation of daily ET within $3 \times 3$ pixel windows centered on the validation sites. The result $\left(0.4 \mathrm{~mm} . \mathrm{d}^{-1}\right)$ indicated that the spatial variability of the ASTER data in the neighborhood of the validation sites had no significant influence on the validation exercise.

Validation of ASTER / S-SEBI predictions against HYDRUS-1D estimates for the seven sites are displayed in Fig. 2. For daily ET ranging between 0 and $5 \mathrm{~mm} . \mathrm{d}^{-1}$ throughout two vineyard growth cycles, RMSE was 0.8 mm.d ${ }^{-1}(30 \%$ in relative), and $\mathrm{R}^{2}$ was about 0.74 . This was better than reports from [12], [14], [13] for finer $(\leq 20 \mathrm{~m})$ and coarser $(\sim 1 \mathrm{~km})$ spatial resolutions (between 1 and $\left.1.5 \mathrm{~mm} . \mathrm{d}^{-1}\right)$.

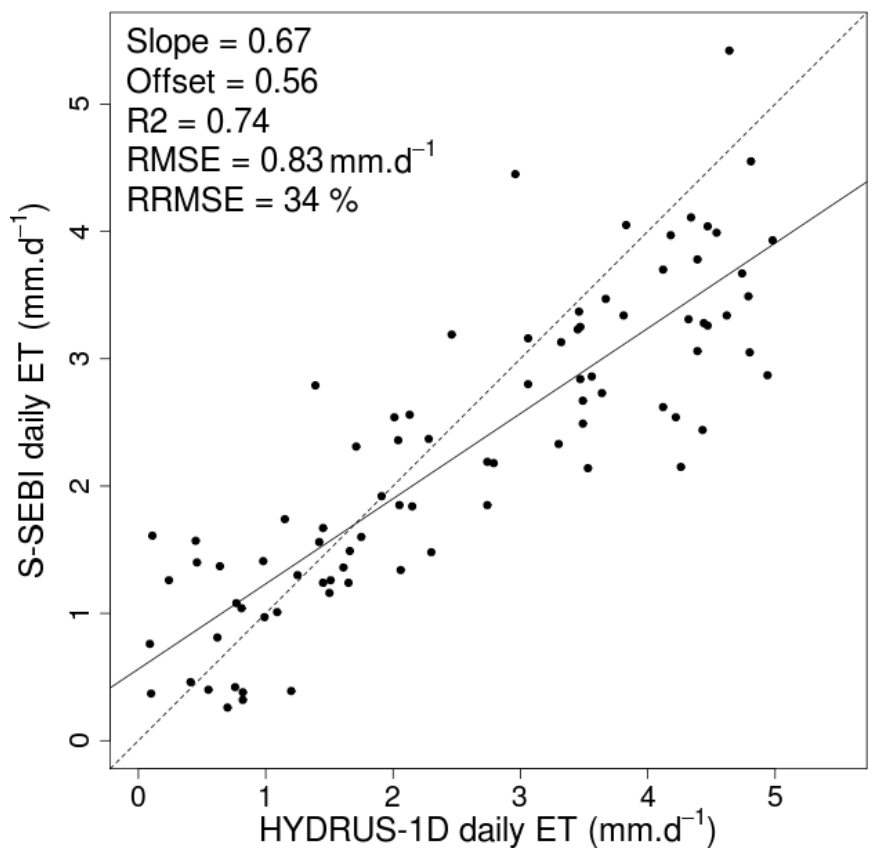

Fig. 2. Comparison, over the seven sites, of ASTER / S-SEBI daily ET estimates against those derived from HYDRUS-1D. $\mathrm{R}^{2}$ is coefficient of determination, Slope and Offset are from linear regression between predictions and references (continuous line). RMSE and RRMSE are absolute and relative Root Mean Square Error, respectively. Dashed line is the 1:1 line.

RMSE was lower $\left(0.6\right.$ mm.d $\left.\mathrm{d}^{-1}\right)$ when replacing HYDRUS-1D estimates by EC measurements. These errors were ascribed to the assumptions S-SEBI relies on, such as similar micrometeorological and aerodynamic conditions for all surfaces, or equivalence between daily and instantaneous values of $\Lambda$.

On a yearly basis, remote sensing and in situ estimates agreed better in 2008 (Tab. II). On a daily basis, relative RMSE was better $(27 \%)$ in spring than in summer $(38 \%)$ and autumn (44\%). These results were ascribed to poorer S-SEBI performances when variability in water conditions was lower.

Validation results on a site basis indicated low unsystematic and large systematic errors. Statistical indicators (Tab. II) were compared against watertable conditions, soil type, row orientation, and soil color. First, RMSE decreased when row orientation changed from $-50^{\circ}$ West to $+90^{\circ}$ East (North being $0^{\circ}$ ), with a $0.5 \mathrm{R}^{2}$ value. This was ascribed to shade effects on the ASTER data, and may also result from coupling between wind direction and row orientation [29]. Second, slope and offset were correlated ( $\mathrm{R}$ value of 0.63 ) with the HYDRUS$1 \mathrm{D}$ calibration residual error, where the latter was averaged for each site over temporal chronicles.

Overall, although there were doubts about using a very simple model over a complex vineyard landscape, the first results reported here showed S-SEBI performances were similar to those obtained over simpler canopies with full covers. Partial influences from row orientation suggested probable (resp. possible) radiative (resp. aerodynamic) behaviors induced by row structure. Furthermore, S-SEBI performances depended on agreement between supposed and captured spatial variabilities. However, theoretically deriving outer limits would require characterizing micrometeorological and aerodynamic 
TABLE II

STATISTICAL INDICATORS WHEN COMPARING HYDRUS-1D AND S-SEBI eStimates: ABsolute (MM.D ${ }^{-1}$ ) AND Relative (\%) RMSE, SLOPE (-) AND OFFSET (MM.D ${ }^{-1}$ ) FROM LINEAR REGRESSION BETWEEN

PREDICTIONS AND REFERENCES, COEFFICIENT OF DETERMINATION (-).

COLUMNS 2-9 ARE RELATED TO YEARS 2007 AND 2008 FOR EACH

VALIDATION SITE. COLUMNS 10-11 ARE RELATED TO ALL VALIDATION SITES FOR 2007 AND 2008 YEAR.

\begin{tabular}{l|llllllll|ll} 
Site & 1 & 2 & 3 & 4 & 5 & $6 \mathrm{~N}$ & $6 \mathrm{~S}$ & 7 & 2007 & 2008 \\
\hline ARMSE & 0.99 & 0.54 & 0.59 & 0.64 & 0.98 & 0.69 & 0.72 & 1.30 & 0.69 & 0.88 \\
RRMSE & 40 & 26 & 28 & 23 & 23 & 31 & 26 & 60 & 57 & 30 \\
Slope & 0.55 & 0.74 & 0.77 & 0.94 & 0.62 & 0.65 & 0.80 & 0.45 & 0.76 & 0.68 \\
Offset & 0.85 & 0.32 & 0.51 & 0.01 & 0.41 & 0.56 & 0.77 & 0.62 & 0.52 & 0.49 \\
$\mathrm{R}^{2}$ & 0.76 & 0.86 & 0.90 & 0.71 & 0.96 & 0.79 & 0.86 & 0.83 & 0.52 & 0.69
\end{tabular}

conditions (e.g. WDI, SEBI), and would be therefore subject to errors in such characterizations.

\section{ACKNOWLEDGMENTS}

The authors thank LISAH technical staff for the experiment, and Jet Propulsion Laboratory for ASTER data collection. This study was funded by Chilean National Commission for Scientific and Technological Research, by French National Institute for Agricultural Research, and by French National Program for Remote Sensing.

\section{REFERENCES}

[1] R. Moussa, N. Chahinian, and C. Bocquillon, "Distributed hydrological modelling of a mediterranean mountainous catchment - model construction and multi-site validation," Journal of Hydrology, vol. 337, no. 1-2, pp. $35-51,2007$.

[2] S. Ortega-Farias, M. Carrasco, A. Olioso, C. Acevedo, and C. Poblete, "Latent heat flux over Cabernet Sauvignon vineyard using the Shuttleworth and Wallace model," Irrigation Science, vol. 25, no. 2, pp 161-170, 2007.

[3] P. Zarco-Tejada, A. Berjon, R. Lopez-Lozano, J. Miller, P. Martin, V. Cachorro, M. Gonzalez, and A. de Frutos, "Assessing vineyard condition with hyperspectral indices: Leaf and canopy reflectance simulation in a row-structured discontinuous canopy," Remote Sensing of Environment, vol. 99, no. 3, pp. $271-287,2005$.

[4] D. Courault, B. Seguin, and A. Olioso, "Review on estimation of evapotranspiration from remote sensing data: From empirical to numerical modeling approaches," Irrigation and Drainage Systems, vol. 19, no. 3, pp. 223 - 249, 2005.

[5] J. Kalma, T. McVicar, and M. McCabe, "Estimating Land Surface Evaporation: A Review of Methods Using Remotely Sensed Surface Temperature Data," Surveys in Geophysics, vol. 29, no. 4-5, pp. 421469,2008

[6] C. van der Tol, W. Verhoef, J. Timmermans, A. Verhoef, and Z. Su, "An integrated model of soil - canopy spectral radiances, photosyntesis, fluorescence, temperature and energy balance," Biogeosciences, vol. 6, no. 12 , pp. $3109-3129,2009$.

[7] F. Jacob, A. Olioso, X. F. Gu, Z. Su, and B. Seguin, "Mapping surface fluxes using airborne visible near infrared, thermal infrared remote sensing data and a spatialized surface energy balance model," Agronomie, vol. 22, pp. 669-680, 2002.

[8] A. French, T. Schmugge, J. Ritchie, A. Hsu, F. Jacob, and K. Ogawa, "Detecting land cover change at the Jornada experimental range, New Mexico with ASTER emissivities," Remote Sensing of Environment, vol. 112 , no. 4 , pp. $1730-1748,2008$

[9] M. Menenti and B. J. Choudhury, In: Exchange Processes at the Land Surface for a Range of Space and Time Scales. IAHS, 1993, vol. 212, ch. Parameterization of land surface evaporation by means of location dependent potential evaporation and surface temperature range, pp. 561568.

[10] M. Moran, T. Clarke, Y. Inoue, and A. Vidal, "Estimating crop water deficit using the relation between surface-air temperature and spectral vegetation index," Remote Sensing of Environment, vol. 49, no. 3, pp. $246-263,1994$.
[11] G. J. Roerink, Z. Su, and M. Menenti, "S-SEBI: A simple remote sensing algorithm to estimate the surface energy balance," Physics and Chemistry of the Earth, Part B: Hydrology, Oceans and Atmosphere, vol. 25 , no. 2 , pp. $147-157,2000$.

[12] M. Gomez, A. Olioso, J. Sobrino, and F. Jacob, "Retrieval of evapotranspiration over the Alpilles/ReSeDA experimental site using airborne POLDER sensor and a thermal camera," Remote Sensing of Environment, vol. 96, pp. 399-408, 2005.

[13] J. Sobrino, M. Gomez, J. Jimenez-Munoz, and A. Olioso, "Application of a simple algorithm to estimate daily evapotranspiration from NOAA-AVHRR images for the Iberian Peninsula," Remote Sensing of Environment, vol. 110, no. 2, pp. 139 - 148, 2007.

[14] J. Sobrino, M. Gomez, J. Jimenez-Munoz, A. Olioso, and G. Chehbouni, "A simple algorithm to estimate evapotranspiration from DAIS data: Application to the DAISEX campaigns," Journal of Hydrology, vol. 315, no. $1-4$, pp. $117-125,2005$

[15] W. W. Verstraeten, F. Veroustraete, and J. Feyen, "Estimating evapotranspiration of European forests from NOAA-imagery at satellite overpass time: Towards an operational processing chain for integrated optical and thermal sensor data products," Remote Sensing of Environment, vol. 96, no. 2, pp. $256-276,2005$

[16] W. Trambouze and M. Voltz, "Measurement and modelling of the transpiration of a Mediterranean vineyard," Agricultural and Forest Meteorology, vol. 107, pp. 153 - 166, 2001

[17] A. V. Dijk, A. Moene, and H. D. Bruin, "The principle of surface flux physics: theory, practice and description of the ECPACK library," Internal Report 2004/1, Meteorology and Air Quality Group, Wageningen University, Wageningen, THe Netherlands, 99p, Tech. Rep., 2004.

[18] J. Simunek and M. T. van Genuchten, "Modeling Nonequilibrium Flow and Transport Processes Using HYDRUS," Vadose Zone Journal, vol. 7 , pp. 782-797, 2008.

[19] C. Riou, P. Pieri, and B. Le Clech, "Consommation d'eau de la vigne en conditions hydriques non limitantes. Formulation simplifiée de la transpiration," Vitis, vol. 33, pp. 109 - 115, 1994.

[20] A. Bsaibes, "Évaluation d'une approche multi-locale d'estimation spatiale de l'évapotranspiration," Ph.D. dissertation, Université de Montpellier II, 2007.

[21] R. Feddes, P. Kowalik, and H. Zaradny, Simulation of field water use and crop yield. Simulation monographs. PUDOC, Wageningen, 189 pp., 1978.

[22] M. van Genuchten, "A closed-form equation for predicting the hydraulic conductivity of unsaturated soils," Soil Science Society of America Journal, vol. 44, pp. 892-898, 1980.

[23] K. Thome, K. Arai, S. Hook, H. Kieffer, H. Lang, T. Matsunaga, A. Ono, F. Palluconi, H. Sakuma, P. Slater, T. Takashima, H. Tonooka, S. Tsuchida, R. M. Welch, and E. Zalewski, "ASTER preflight and inflight calibration and the validation of Level 2 products," IEEE Transactions on Geoscience and Remote Sensing, vol. 36, pp. 11611172, Jul. 1998.

[24] F. Jacob, T. Schmugge, A. Olioso, A. French, D. Courault, K. Ogawa, F. Petitcolin, G. Chehbouni, A. Pinheiro, and J. Privette, "Modeling and inversion in thermal infrared remote sensing over vegetated land surfaces," in Advances in Land Remote Sensing: System, Modeling, Inversion and Application, S. Liang, Ed. Springer, 2008, pp. 245-292.

[25] F. Jacob, A. Olioso, M. Weiss, F. Baret, and O. Hautecoeur, "Mapping short-wave albedo of agricultural surfaces using airborne PolDER data," Remote Sensing of Environment, vol. 80, pp. 36-46, 2002.

[26] S. Liang, "Narrowband to broadband conversions of land surface albedo I: Algorithms," Remote Sensing of Environment, vol. 76, no. 2, pp. 213 238, 2001.

[27] K. Ogawa, T. Schmugge, F. Jacob, and A. French, "Estimation of land surface window $(8-12 \mu \mathrm{m})$ emissivity from multi-spectral thermal infrared remote sensing - A case study in a part of Sahara Desert," Geophysical Research Letters, vol. 30, no. 2, p. 1067, 2003.

[28] W. G. M. Bastiaanssen, M. Menenti, R. A. Feddes, and A. A. M. Holtslag, "A remote sensing surface energy balance algorithm for land (SEBAL). 1. Formulation," Journal of Hydrology, vol. 212-213, pp. $198-212,1998$

[29] J. Heilman, K. McInnes, M. Savage, R. Gesch, and R. Lascano, "Soil and canopy energy balances in a west Texas vineyard," Agricultural and Forest Meteorology, vol. 71, no. 1-2, pp. 99 - 114, 1994. 